\title{
Ultrasonography Findings of AlloDerm ${ }^{\circledR}$ Used in Postmastectomy Alloplastic Breast Reconstruction: A Case Report and Literature Review
}

\author{
Young Seon $\mathrm{Kim}^{1, *}$ \\ ${ }^{1}$ Department of Radiology, College of Medicine, Yeungnam University, Daegu, Korea \\ "Corresponding author: Young Seon Kim, Department of Radiology, College of Medicine, Yeungnam University, 170, Hyeonchung-ro, Nam-gu, Daegu, Korea. Tel: +82-26204129, \\ Fax: +50-43738795, E-mail: ing29@hanmail.net
}

Received 2016 April 10; Accepted 2016 April 21.

\begin{abstract}
AlloDerm $^{\circledR}$ (LifeCell Corp.; Brancburg, NJ) is an acellular dermal matrix (ADM) that serves as an immunologically inert scaffold in plastic surgery. In breast reconstruction, it is used as a filler for lumpectomy defects and can be used to create the inferolateral portion of the tissue expander pocket or implant pocket in postmastectomy patients. However, there are limited reports of the radiologic findings of AlloDerm ${ }^{\circledR}$ in patients who have undergone postmastectomy reconstruction. Familiarity with the imaging features of AlloDerm ${ }^{\circledR}$ is essential for correct diagnosis. We report the ultrasonography features of AlloDerm ${ }^{\circledR}$ in a 43-year-old female patient 3 months after postmastectomy reconstruction. It may help distinguish AlloDerm ${ }^{\circledR}$ from tumor recurrence or other foreign body materials such as gossypiboma. This is important as misdiagnosis can often lead to unnecessary surgical intervention.
\end{abstract}

Keywords: Alloderm ${ }^{\circledR}$, Breast Reconstruction, Mastectomy, Ultrasonography

\section{Introduction}

AlloDerm $^{\circledR}$ (LifeCell Corp.; Brancburg, NJ) is an acellular dermal matrix (ADM) obtained from cadaveric human skin that has been processed to remove all antigenic epitopes and cells, resulting in an immunologically inert scaffold (1-3). The remaining dermal matrix contains collagen, elastin, hyaluronic acid, fibronectin, proteoglycans, growth factor receptors and vascular channels, which allow for host cell migration and angiogenesis $(1,3,4)$. AlloDerm ${ }^{\circledR}$ has previously been used in breast reconstruction (5, 6), abdominal hernia repair (7-9), pelvic reconstruction $(10,11)$, as well as head and neck contouring and reconstruction $(12,13)$.

In current practice, AlloDerm ${ }^{\circledR}$ has become increasingly popular in plastic surgery, particularly breast reconstruction (1). It is used as a filler for lumpectomy defects (2, 3) and can be used to create the inferolateral portion of the tissue expander pocket or implant pocket in postmastectomy patients $(1,6)$. However thus far, only a small number of reports have described the radiologic findings of AlloDerm ${ }^{\circledR}$ in postmastectomy reconstruction patients (2, $3,14)$. This poses a diagnostic challenge, as radiologists may be unfamiliar with the imaging features of AlloDerm ${ }^{\circledR}$. Buck et al. reported the case of a patient with a new palpable mass in her breast after mastectomy (15). After surgical excision, it was confirmed to be a foreign body giant cell infiltration, secondary to the ADM used in reconstruction (15). We herein report the ultrasonography features of AlloDerm ${ }^{\circledR}$ in a 43 -year-old female patient, 3 months after postmastectomy reconstruction. Enhanced characterization of this finding may help in distinguishing it from tumor recurrence or other foreign body material such as gossypiboma. This is important as misdiagnosis can often lead to unnecessary surgical intervention.

\section{Case Presentation}

A 43-year-old woman, who underwent left skin-sparing mastectomy for ductal carcinoma in situ 2 years before and delayed reconstruction 3 months before presentation, developed a palpable mass along the lower lateral aspects of her reconstructed left breast. Signs and symptoms suggesting inflammation, such as fever, tenderness, localized warmth or redness were not present. A targeted ultrasound examination was performed, and a $1.7 \times 0.7 \times 3.3$ centimeter mass with smooth margins observed at the lower lateral aspect of the left breast, along the superficial margin of implant (Figure 1A). It appeared oval-shaped on transverse view (Figure $1 \mathrm{~A}$ ), whereas on the longitudinal view, it had a folded, sheet like structure (Figure 1B). The lesion did not show vascularity on color Doppler imaging (Figure 1C). A left mediolateral oblique view (MLO) mammography demonstrated a band-like lesion at the lower 
aspect of the reconstructed left breast. The palpable area of concern (marked with BB marker on skin) was isodense to the surrounding glandular tissue (Figure 1D). On simple chest radiography, a band-like structure was demonstrated overlapping her reconstructed left breast (Figure $1 \mathrm{E})$. This was not seen on her previous chest radiograph, performed prior to the reconstruction surgery (Figure 1F). Non-enhanced computed tomography (CT) of the chest demonstrated an oval-shaped lesion with soft tissue density along the superficial aspect of the implant (Figure $1 G)$. After discussion with the plastic surgeon, this location and configuration was identified as consistent with the AlloDerm ${ }^{\circledR}$ sling used in reconstruction surgery. Therefore, our final assessment was Breast Imaging Reporting and Data System (BI-RADS) category 2 (benign finding). The patient is currently doing well without evidence of recurrence of breast cancer.

\section{Discussion}

There are many different options for postmastectomy breast reconstruction. However, the application of ADM has become one of the main options for implant-based breast reconstruction (16). ADM has many benefits over the traditional submuscular technique. These include, enhanced lower pole expansion, easier definition of the inframammary fold (IMF), a reduction in postoperative pain, and improved cosmetic outcomes $(5,6,15,16)$. Thus, its use in breast reconstruction has become increasingly popular.

In postmastectomy patients, the pectoralis major muscles frequently provide insufficient inferolateral coverage for the tissue expander or implant, especially in thin women (5). The AlloDerm ${ }^{\circledR}$ sling technique was first introduced by Breuing and Warren in 2005 (5). AlloDerm ${ }^{\circledR}$ is sewn to the inferior edge of the pectoralis major muscle and along the chest wall at the location of the inframammary fold, creating a subpectoral-sub-AlloDerm ${ }^{\circledR}$ pocket (5). When placed at a well-vascularized surface, AlloDerm ${ }^{\circledR}$ incorporates into the host tissue, forming a new matrix for tissue regeneration $(17,18)$.

Imaging studies after breast reconstruction with AlloDerm ${ }^{\circledR}$ are usually performed for diagnostic evaluation of postoperative complication, clinical concern of palpability, or pain. It may be diagnostically challenging for radiologists, if they are unfamiliar with the imaging appearance of AlloDerm ${ }^{\circledR}$ used in breast reconstruction. Buck et al. reported the case of a patient with a new palpable mass in her breast after mastectomy (15). After surgical excision, it was confirmed to be a foreign body giant cell infiltration, secondary to the ADM used in reconstruction (15).
However, few reports exist describing the radiologic findings of AlloDerm ${ }^{\circledR}$ cases of postmastectomy reconstruction $(2,3,14)$. On mammography, AlloDerm ${ }^{\circledR}$ is isodense to glandular tissue without obscuring calcifications and it may resemble postoperative changes, seromas, or hematomas $(2,3)$. Tran Cao et al. described an ultrasound feature of AlloDerm ${ }^{\circledR}$ in the setting of seroma, as an echogenic band with posterior acoustic shadowing (2). Additionally, Lee et al. described an ultrasound of AlloDerm ${ }^{\circledR}$ use in postmastectomy reconstruction, as multiple isoechoic, vague parallel hypoechoic to isoechoic masses with smooth margins, with and without color flow (3). They suggested that the variability of sonographic features could reflect the continuum of vascularization and incorporation of AlloDerm ${ }^{\circledR}$ into the host (3). AlloDerm ${ }^{\circledR}$ also showed variable appearance on MRI $(2,3,14)$; iso-signal intensity to glandular tissue on non fat-saturated T1-weighted image, and hypersignal intensity on fat-saturated T2-weighted image with non- to mild enhancement on dynamic contrastenhanced MRI.

Enhanced radiologic characterization of AlloDerm ${ }^{\circledR}$ may help in distinguishing it from tumor recurrence, postoperative change, fat necrosis, abscess or other foreign body material such as a gossypiboma. Careful correlation with the operative record and discussion with the surgeon may also be helpful in aiding a diagnosis. This is important in preventing a misdiagnosis and potentially unnecessary surgical intervention.

\section{Acknowledgments}

The study design was approved by the appropriate ethics review boards.

\section{Footnotes}

Authors' Contributions: Young Seon Kim analyzed or interpreted the data, drafted and revised the manuscript, designed or conceptualized the study.

Conflicts of Interest: There are no conflicts of interest to declare.

Funding/Support: There are no funding or support to declare. 

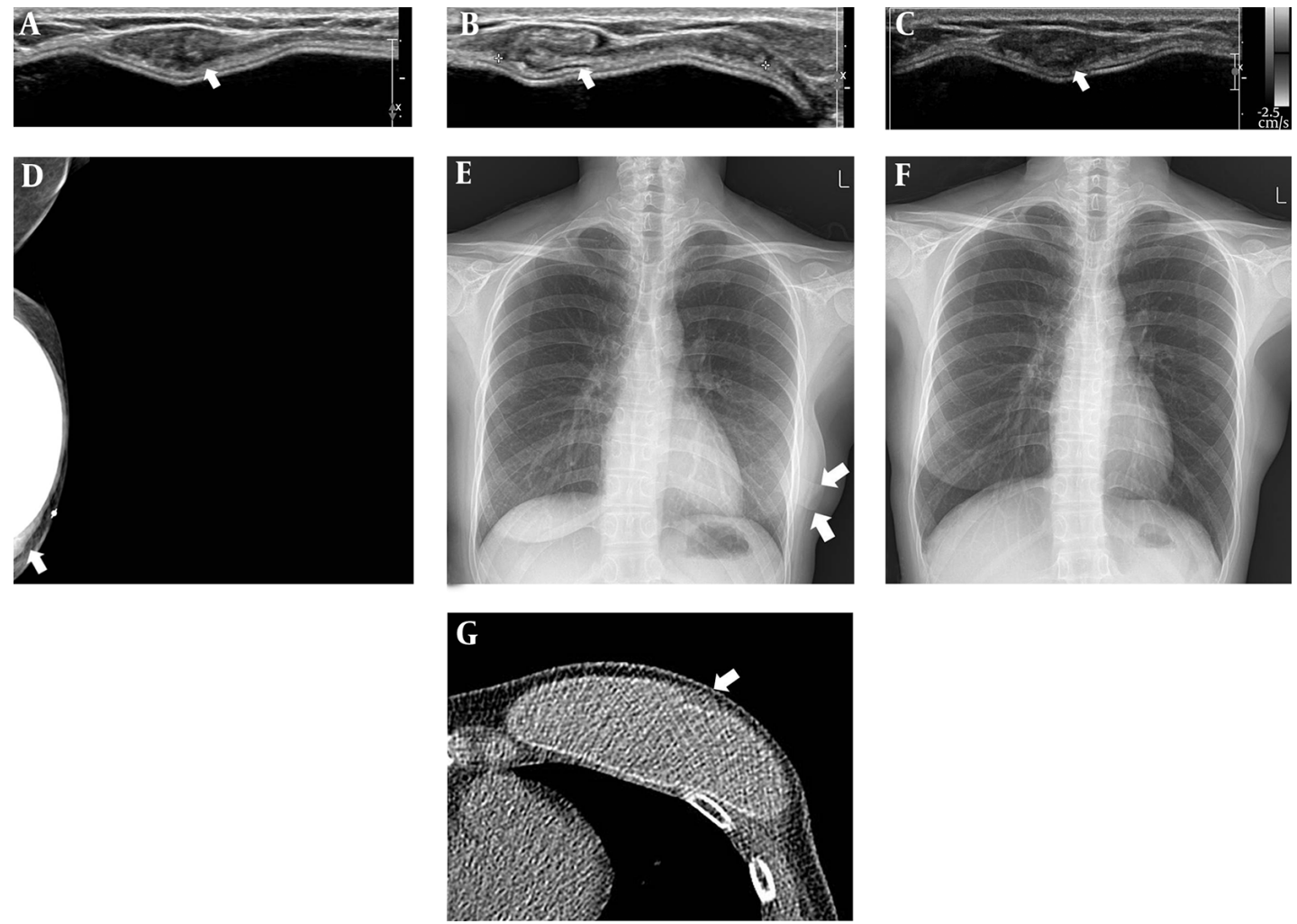

Figure 1. A 43-year-old woman with left mastectomy and reconstruction with implant. A - C, Ultrasonography demonstrates an isoechoic mass with smooth margin at left lower outer breast along the superficial margin of implant. It was oval-shaped on transverse view, and a folded, sheet-like structure on longitudinal view, the lesion did not show vascularity on color Doppler imaging; D, Left MLO demonstrated an isodense, band-like structure at the location of concern (marked with BB marker on skin); E, On chest radiographs, a radiopaque band-like structure was demonstrated overlapping the reconstructed left breast (annotated with arrow); It was not shown on the previous chest radiograph, performed prior to reconstruction surgery (F); G, Non-enhanced computed tomography of the chest demonstrated an oval shaped, lesion with soft tissue density along the superficial aspect of implant.

\section{References}

1. Jansen LA, Macadam SA. The use of AlloDerm in postmastectomy alloplastic breast reconstruction: part I. A systematic review. Plast Reconstr Surg. 2011;127(6):2232-44. doi: 10.1097/PRS.ob013e3182131c56. [PubMed: 21617458].

2. Tran Cao HS, Tokin C, Konop J, Ojeda-Fournier H, Chao J, Blair SL. A preliminary report on the clinical experience with AlloDerm in breast reconstruction and its radiologic appearance. Am Surg. 2010;76(10):1123-6. [PubMed: 21105625].

3. Lee CU, Clapp AJ, Jacobson SR. Imaging Features of AlloDerm((R)) Used in Postmastectomy Breast Reconstructions. J Clin Imaging Sci. 2014;4:19. doi: 10.4103/2156-7514.131641. [PubMed: 24987566].

4. Gabriel A, Maxwell GP. Evolving role of alloderm in breast surgery. Plast Surg Nurs. 2011;31(4):141-50. doi: 10.1097/PSN.0b013e31823b2c30. [PubMed: 22157603].

5. Breuing $\mathrm{KH}$, Warren SM. Immediate bilateral breast reconstruction with implants and inferolateral AlloDerm slings. Ann Plast Surg. 2005;55(3):232-9. [PubMed: 16106158].

6. Spear SL, Seruya M, Rao SS, Rottman S, Stolle E, Cohen M, et al. Two-stage prosthetic breast reconstruction using AlloDerm including outcomes of different timings of radiotherapy. Plast Reconstr Surg. 2012;130(1):1-9. doi: 10.1097/PRS.0b013e3182547a45. [PubMed: 22743866].
7. Buinewicz B, Rosen B. Acellular cadaveric dermis (AlloDerm): a new alternative for abdominal hernia repair. Ann Plast Surg. 2004;52(2):18894. doi: 10.1097/01.sap.0000100895.41198.27. [PubMed: 14745271].

8. Butler CE, Prieto VG. Reduction of adhesions with composite AlloDerm/polypropylene mesh implants for abdominal wall reconstruction. Plast Reconstr Surg. 2004;114(2):464-73. [PubMed:15277815].

9. Menon NG, Rodriguez ED, Byrnes CK, Girotto JA, Goldberg $\mathrm{NH}$, Silverman RP. Revascularization of human acellular dermis in full-thickness abdominal wall reconstruction in the rabbit model. Ann Plast Surg. 2003;50(5):523-7. doi: 10.1097/01.SAP.0000044252.76804.6B. [PubMed: 12792544].

10. Butler CE, Langstein HN, Kronowitz SJ. Pelvic, abdominal, and chest wall reconstruction with AlloDerm in patients at increased risk for mesh-related complications. Plast Reconstr Surg. 2005;116(5):1263-75. [PubMed: 16217466].

11. Clemons JL, Myers DL, Aguilar VC, Arya LA. Vaginal paravaginal repair with an AlloDerm graft. Am J Obstet Gynecol. 2003;189(6):1612-8. [PubMed: 14710083].

12. Jackson IT, Yavuzer R. AlloDerm for dorsal nasal irregularities. Plast Reconstr Surg. 2001;107(2):553-8. [PubMed: 11214075].

13. Sinha UK, Chang KE, Shih CW. Reconstruction of pharyngeal defects using AlloDerm and sternocleidomastoid muscle flap. Laryngoscope. 2001;111(11 Pt 1):1910-6. doi: 10.1097/00005537-20011100000007. [PubMed: 11801968].

14. Dialani V, Lai KC, Slanetz PJ. MR imaging of the reconstructed breast: What the radiologist needs to know. Insights Imaging. 2012;3(3):201-13. 
doi: 10.1007/s13244-012-0150-7. [PubMed: 22696083].

15. Buck DW, Heyer K, Wayne JD, Yeldandi A, Kim JY. Diagnostic dilemma: acellular dermis mimicking a breast mass after immediate tissue expander breast reconstruction. Plast Reconstr Surg. 2009;124(1):174-6. doi: 10.1097/PRS.0b013e3181a83c69. [PubMed: 19568066].

16. Lee KT, Mun GH. Updated Evidence of Acellular Dermal Matrix Use for Implant-Based Breast Reconstruction: A Meta-analysis. Ann Surg Oncol. 2016;23(2):600-10. doi: 10.1245/s10434-015-4873-9. [PubMed: 26438439].
17. Novitsky YW, Rosen MJ. The biology of biologics: basic science and clinical concepts. Plast Reconstr Surg. 2012;130(5 Suppl 2):9S-17S. doi 10.1097/PRS.0b013e31825f395b. [PubMed: 23096994].

18. McCarthy CM, Lee CN, Halvorson EG, Riedel E, Pusic AL, Mehrara $\mathrm{BJ}$, et al. The use of acellular dermal matrices in two-stage expander/implant reconstruction: a multicenter, blinded, randomized controlled trial. Plast Reconstr Surg. 2012;130(5 Suppl 2):57S-66S. doi: 10.1097/PRS.0b013e31825fo5b4. [PubMed: 23096987]. 